\title{
MUDANÇAS AMBIENTAIS QUATERNÁRIAS NA PORÇÃO SUBMÉDIA DA PLANÍCIE DO SÃO FRANCISCO: RECONSTRUÇÃO AMBIENTAL
}

QUATERNARY ENVIRONMENTAL CHANGES IN THE SUBMIDDLE REACH OF SÃO FRANCISCO RIVER

FLOODPLAINS: AN ENVIRONMENTAL RECONSTRUCTION

\author{
Daniel Rodrigues de Lira ${ }^{1}$ \\ dniellira@gmail.com
}

\begin{abstract}
The analysis of superficial deposits allows the reconstruction the environmental dynamics of the study area within a given palaeo-environmental time frame. The Oxisols developed on the Sao Francisco floodplain deposits, originate from the lowering of water-table levels in the river banks and the subsequent emergence of sandy bars, some of which were reworked by wind erosion during periods of stronger semi-aridity, resulting in the accumulation of dune fields and sand mantles in wetter periods. Later on, some of these deposits were reworked by the floods of the São Francisco River. The results of this research point to a climatic genesis of landforms, driven by general circulation controls, thus revealing the role of important atmospheric teleconnection events in the area occurring since the Last Glacial Maximum - LGM, through the Pleistocene/Holocene transition until the Upper Holocene.
\end{abstract}

Keywords: evolution of the landscape; superficial deposits; semiarid.

\footnotetext{
${ }^{1}$ Docente, Departamento de Ciências Geográficas, UFPE.
} 


\section{RESUMO}

A dinâmica dos acontecimentos geomorfológicos e sua evolução tornam-se necessárias para elucidar a história recente da paisagem. Nessa perspectiva a análise de depósitos superficiais permitiu a reconstrução das dinâmicas ambientais para a região com ênfase temporal/paleoambiental. Os Latossolos que integram a Planície do Rio São Francisco têm origem a partir do rebaixamento de suas águas e surgimento de barras arenosas retrabalhadas pelo vento em períodos de maior semiaridez formando campos de dunas; em períodos mais úmidos, mantos de areia, sendo estes retrabalhados em momentos de cheias, originando depósitos arenosos na planície fluvial. Os estudos indicam uma gênese climática controlada por fatores da circulação geral da atmosfera em nível global e regional, revelando tele conexões importantes desde o Último Máximo Glacial - UMG, transição Pleistoceno/Holoceno até o Holoceno Superior.

Palavras-chave: evolução da paisagem; depósitos superficiais; semiárido.

\section{CONTEXTO DA PESQUISA}

A análise da dinâmica geomorfológica dos sedimentos, onde hoje são desenvolvidos os Latossolos na porção Submédia da Bacia do Rio São Francisco no Oeste pernambucano pode favorecer a avaliação da existência de controles temporais significativos e recorrentes no passado, além da sua extrapolação para os sistemas de superfícies terrestres contemporâneos, para isso é necessária a compreensão dos mecanismos formadores dos Latossolos em clima semiárido e suas relações geomorfológicas.

Através da análise dos depósitos é possível interpretar a história da deposição, lançando luz sobre os processos formadores dos materiais superficiais. Desta forma a diferenciação dos tipos de depósitos ajuda a elucidar com maior facilidade o evento formativo possibilitando aventar hipóteses mais fidedignas 
sobre a evolução da paisagem e suas tendências temporais, bem como essas mudanças afetaram a distribuição e o padrão das ocupações Pré-históricas no semiárido nordestino, a discussão sobre processo de ocupação de diferentes regiões no território nordestino, durante o Holoceno tem sido marcada por existências de hiatos regionais com durações distintas, podendo ser explicadas para esta região a partir das variações paleoambientais, decorrentes das mudanças do clima global e regional (MÜTZENBERG 2007; 2010).

Para Lang e Hönscheidt (1999), o termo colúvio é usado para sedimentos gerados pela erosão do solo e transportados ao longo do declive. Segundo Smolska (2006), os mecanismos de transporte de sedimentos podem caracterizar como também evidenciar a origem do material, os depósitos aluviais caracterizam-se facilmente por seções definidas indicando tração e salto dos grãos. Corrêa et. al. (2008) afirmam que a topografia superficial e a morfologia dos corpos litológicos desempenham um papel primordial no controle do fluxo de superfície e da estabilidade de encostas nessa área. Este estudo reforça a importância da abordagem morfoestratigráfica, e demonstra que no caso dos depósitos recentes os controles topográficos sobre a deposição são geralmente os mais importantes.

\section{Latossolos e suas relações com as Superfícies de Aplainamento}

Vários foram os estudos desenvolvidos em diferentes regiões do Brasil, correlacionando, ainda que de forma generalizada, a ocorrência dos Latossolos com superfícies de aplainamento, mesmo antes da publicação das superfícies 
reconhecidas por King (1956) para o Brasil oriental, algumas delas depois estendidas para o resto do território brasileiro de acordo com Braum (1982), Apud Lepsch e Buol (1986). Diversos autores relacionaram evolução de solos a geomorfologia, entre eles Lepsch (1977a, 1977b), Ab’Saber (1962), com as stone lines, Bigarella et al. (1965a, 1965b) que além de cascalheiras (stone lines), acrescentam os horizontes escurecidos (paleossolos) recobertos por colúvio.

Registram-se discussões sobre a natureza alóctone ou autóctone imposta a muitos dos materiais dos quais, presumivelmente, os latossolos originaram-se. A maioria desses solos está estabelecida sobre velhas e estáveis superfícies geomórficas (BUOL et. al., 1980). Muitos consideram que as suas características são resultado de uma pedogênese policíclica, iniciada em sedimentos situados relativamente próximos de suas fontes e depositados depois de previamente intemperizados (STOOPS, 1989, 1997; MUGGLER, 1998). Outros consideram esses materiais provenientes da profunda alteração de material similar ao imediatamente adjacente (MILLOT, 1977), com ocorrências de remanejamentos localizados e grandemente influenciados por remontes verticais causados pela biopertubação (ESCHENBRENNER, 1996), sem que tenha havido necessariamente um tempo relativamente longo de formação do solum (MIKLÓS, 1992). Praticamente estudos desenvolvidos objetivando estabelecer correlações entre as ocorrências de solos com superfícies geomórficas (BENNEMA, 1962 apud QUEIROZ NETO, 2011; QUEIROZ NETO, 2000; ÁVILA e CARVALHO 2002; OLIVEIRA e ÁVILA, 1996; REATTO, et.al. 2010; MOTTA, et.al. 2012, CIOLKOSZ, et.al. 
1990), destacam que esta classe de solos, ocupa preferencialmente as partes mais estáveis da paisagem, normalmente correlacionadas com a Superfície Sul Americana do Terciário Inferior, proposta por King (1956). Um exemplo clássico de remanescente de superfície do ciclo Sul Americano, referem-se às amplas "Chapadas" de relevo plano e suavemente ondulado do Planalto Central, onde normalmente encontram-se os solos mais intemperizados do Brasil.

\section{Problemas e Hipóteses relacionadas aos Latossolos no Semiárido}

Os Latossolos encontrados hoje no Oeste pernambucano (Figura 1) e inseridos na Depressão Sertaneja do Nordeste brasileiro, mais especificamente dentro das Bacias hidrográficas Riacho do Pontal e GI-8, não correspondem ao pedoclima atual da região. Normalmente, nas áreas de clima semiárido do Nordeste do Brasil são encontrados solos jovens e rasos (Neossolos Litólicos, Neossolos Regoliticos, Neossolos Flúvicos, Neossolos Quartzarênicos, Luvissolos, Planossolos), com exceção das bacias sedimentares, onde a topografia plana da cimeira permite a formação de solos profundos e mais evoluídos. Segundo Ker (1997), os Latossolos em climas semiáridos são considerados como solos-testemunhos de condições climáticas pretéritas mais úmidas.

A hipótese da formação dos Latossolos no Oeste pernambucano, segundo Menezes et. al. (2007), seria a evidência do transporte de material sedimentar, corroborado pelo fato desses solos ocorrerem nas baixadas, enquanto que sua posição clássica dentro deste domínio morfoclimático seria sobre as superfícies 
planas de cimeira. Outra evidência é a proximidade das manchas dos solos às áreas do terreno com cotas altimétricas mais elevadas, porém destituídas de significativa cobertura pedológica hodierna. Ainda segundo Menezes et. al. (2007), mesmo que sobre alguns divisores regionais as manchas de Latossolos nesta região possam representar verdadeiras coberturas residuais, na área estudada suas relações geomorfológicas favorecem a interpretação de que se trata de sedimentos quaternários derivados de mantos de intemperismo remobilizados.

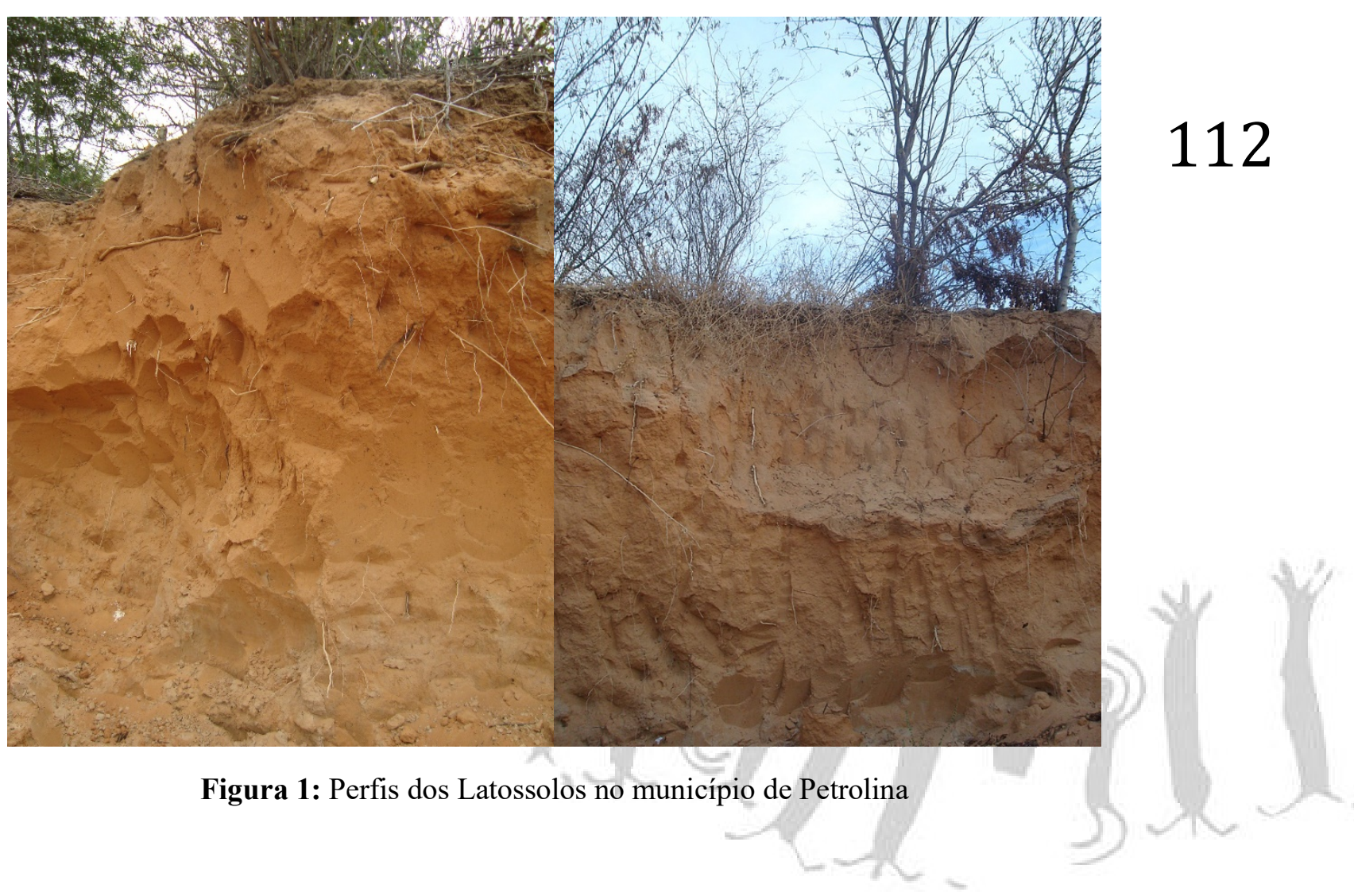


No estado de Pernambuco a segunda maior distribuição dos Latossolos encontrase dentro da Depressão Sertaneja (Figura 2).

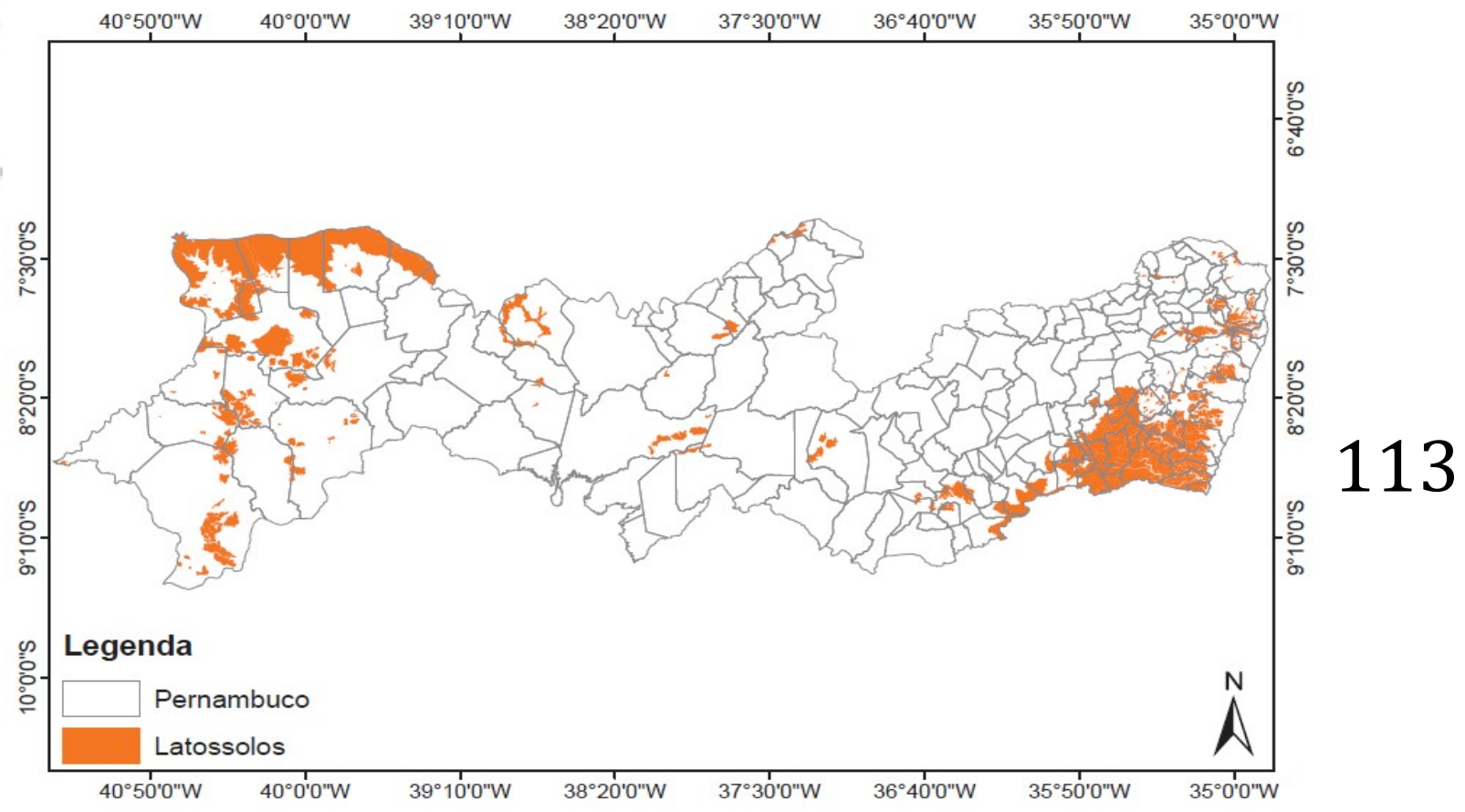

Figura 2: Distribuição dos Latossolos no estado de Pernambuco. Fonte: adaptado de Silva, 2001.

Esta hipótese lastreia a ideia da ocorrência de uma fase de aplainamento, representada morfologicamente na paisagem pela ocorrência de um pediplano de gênese hibrida ou uma dupla superfície de erosão, havendo primeiro atuado a etchplanação, seguida por uma fase de erosão/deposição. A sequência de eventos morfogenéticos descrita acima permite aventar a hipótese de que na região 
ocorreram momentos de climas mais úmidos, geradores de uma topografia mais dissecada, que comportava regolitos mais espessos. Em seguida, deve haver ocorrido uma mudança climática para condições semiáridas. Durante essa nova fase ocorrera o transporte dos materiais argilificados pela decomposição da rocha in situ da fase anterior.

Corrêa (2001) afirma que a paisagem atual é resultado do somatório dos processos históricos que influenciaram diretamente na elaboração e modificação das suas formas. Assim, à medida que os climas secos se prolongaram, houve oportunidade para um reafeiçoamento da paisagem pela pediplanação, restando os inselbergues, e relevos residuais, circundados por níveis de pedimentos que marcam a fase terminal de aplainamento, ultimado pela rápida sucessão de etchplanação seguida por pediplanação extensiva.

Observações preliminares indicam que as definições regionais embasadas nas correntes cíclicas de evolução do relevo, não propiciam uma compreensão das relações de campo entre as formações superficiais e as formas do relevo. Portanto, faz-se necessário estabelecer uma relação clara entre os materiais estruturadores da superfície da paisagem e as formas de relevo. Os limites das formações superficiais podem ser plenamente elucidados através de técnicas de mapeamento de detalhe que associem procedimentos de mapeamento morfológico tradicional (DEMEK e EMBLETON, 1972), com analises de feições morfoestruturais, associadas a análises geoquímicas dos materiais envolvidos, assim como obtenção 
da cronologia dos eventos marcantes para cada unidade geomorfológica ou ainda material superficial, podendo esses serem formados in situ ou provenientes de transporte.

O conhecimento da dinâmica temporal dos acontecimentos geomorfológicos bem como a evolução pedológica faz-se necessário para compreensão da história recente da paisagem. Através da análise dos depósitos superficiais (colúvio/leque aluvial/depósito aluvial/elúvio) é possível interpretar a história da sedimentação, pedogênese e o ambiente deposicional, lançando luz sobre os processos formadores dos materiais superficiais. Desta forma, a diferenciação dos tipos de depósitos ajuda a elucidar com maior facilidade seus eventos geradores, possibilitando criar hipóteses mais fidedignas sobre a evolução da paisagem.

Quando se fala em transporte de sedimentos, existem duas possibilidades, a primeira consiste em produtos de instabilidades de vertentes comumente chamados de colúvios, normalmente coligados a episódios de instabilidade de encostas rochosas alteradas pela ação intempérica que os cooptam a uma procedência residual. Os colúvios podem/ser originados pela desestabilização de solos sedimentares sendo, por vezes, estes próprios solos derivados de coluvionamentos pretéritos em sequências (SANTOS e VIDAL, 2003). A outra forma de transporte de sedimentos dá-se por ação fluvial e os depósitos são comumente chamados de alúvios. Os depósitos de origem fluvial segundo Suguio (1998) e Guerra (2005) tratam-se do acúmulo de materiais detríticos, resultantes 
do carreamento por força fluvial, deposição e sedimentação. Ao longo de canais fluviais ladeados por encostas os coluvios sofrem sobreposição pelos depósitos fluviais da planície de inundação resultando em sequências híbridas de difícil identificação, (LANG. 2003 e MOURIER, et. al. 2008).

Em depósitos mal selecionados de encosta, nem sempre é fácil a diferenciação entre o colúvio e o solo residual, e ainda entre esse e o material aluvial. Devido ao número de fenômenos diferenciados ligados diretamente à formação desses depósitos, e à escassez de trabalhos voltados à elucidação de seus ambientes deposicionais, tornam-se raras as discussões que tratem de suas composições físicas, químicas e estruturais e como estas são alteradas pelos processos erosivos e pedogenéticos.

A diferenciação estratigráfica entre depósitos aluviais e coluviais segundo Amit et. al. (1995) pode ser baseada pela textura, estrutura das fáceis deposicionais, tipo de contato, cor, grau de coesão e de fatores pedogenéticos. Outro critério (KAISER et. al. 2007) é dado pelo teor de matéria orgânica, geralmente o que aponta para uma origem de idade holocênica.

A análise geomorfológica e pedológica de depósitos coluviais ou aluviais pode mostrar o ritmo de produção desses sedimentos, principalmente no acréscimo das terras aráveis e sua susceptibilidade à erosão devido à sua composição mineralógica que deve guardar um grau de proximidade com seu material de 
origem. Uma distinção entre esses sedimentos é de grande utilidade na elaboração de plano de manejo dos solos formados a partir deles, já que solos derivados de alúvios são de alta fertilidade e os de colúvios, normalmente são de baixa fertilidade. Esse fato gera viabilidades econômicas distintas do uso desses solos, que pode ser estimada utilizando como um dos fatores a qualidade dos solos.

\section{A paleoclimatologia do quaternário do nordeste continental}

A fim de estabelecer um quadro paleoclimático é fundamental utilizar os dados contemporâneos como ponto de partida, especialmente em termos de dinâmica atmosférica e padrões sinóticos em escala regional ou continental, sendo necessário por vezes a utilização de uma transposição de dados de áreas análogas (GURGEL et. al., 2013). Esta abordagem institui que mecanismos climatometeorológicos que conduzem à ocorrência de eventos extremos contemporâneos podem ajudar a entender como os processos desencadeadores climáticos poderiam ter trabalhado durante o Pleistoceno Tardio, especialmente aceitando-se que esses padrões sub-recentes de circulação na América do Sul tropical foram afetados em intensidade e distribuição espacial desde o início da UMG (Ultimo Máximo Glacial), em vez de serem inteiramente substituídos por outros diferentes (BRÄUNING, 2009).

O Semiárido pernambucano é particularmente suscetível a episódios de seca, esses estão envolvidos e diretamente ligados a mecanismos que inibem a migração da ZCIT e de outros sistemas de perturbação meteorológicos ao longo da parte norte 
do Brasil (PETERSON e HAUG, 2006). Entre as interferências principais neste movimento, um é amplamente reconhecido por causar o aparecimento de graves secas no nordeste Brasil: os episódios quentes ENOS, também conhecidos como El Niño (HAYLOCK et al., 2006). Por conseguinte, existe uma importante interconexão entre El Niños moderados a fortes no Pacífico tropical sul e seca generalizada no Nordeste do Brasil (OLIVEIRA et al., 1999). De modo semelhante, a ausência de El Niño ou condições semelhantes favorece a ocorrência de chuvas acima do normal na área de estudo. Não surpreendentemente, paleo-ENOS também podem fornecer uma fonte confiável de dados para interpretar os mecanismos que desencadeiam produção de sedimento para a região.

Os primeiros estudos utilizando padrões sedimentológicos e biológicos como indicadores paleoclimáticos naturais (proxies) para recriar a história climática do Pleistoceno tardio do Nordeste do Brasil basearam-se em testemunhos de sedimentos retirados da plataforma continental da região (DAMUTH e FAIRBRIDGE, 1970). Os resultados dos estudos apontaram para uma notável semelhança entre as circulações atmosféricas contemporâneas e as últimas glaciações e penúltima fase interglacial sobre o Nordeste brasileiro. 


\section{ÁREA DE ESTUDO}

\section{Arcabouço geomorfológico da região e aspectos climáticos}

A área em questão encontra-se inserida dentro da unidade morfoestrutural da depressão sertaneja (Figura 3), que compreende uma área dissecada constituída por um embasamento Pré-Cambriano, sua gênese normalmente é relacionada à Teoria da Pediplanação escrita por King (1956). Todavia existem outros fatores que devem ser considerados, como os reflexos da interação de processos morfodinâmicos atuais e pretéritos em sucessão climática que foram dirigidas ou indiretamente subordinadas às alternâncias periódicas de climas úmido, semiárido e árido (SANTOS e SALGADO, 2010).

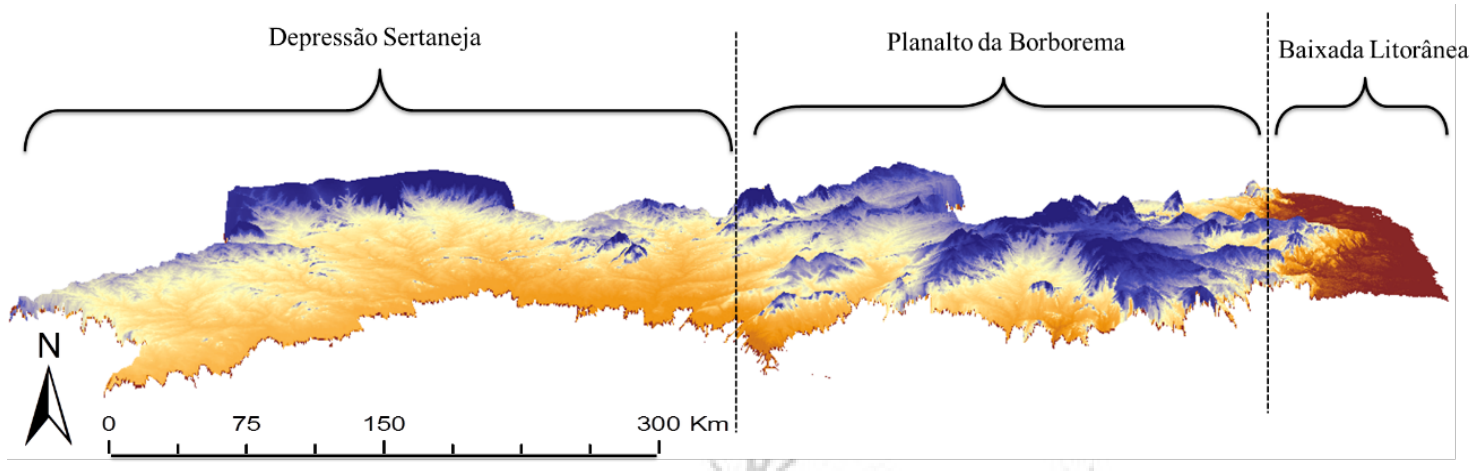

Figura 3: Principais Unidades Morfoestruturais do estado de Pernambuco.

O clima da região, caracteriza-se como semiárido típico (quente e seco), o qual possui duas estações bem diferenciadas: estação seca (entre os meses de maio a outubro) e a estação chuvosa, (entre os meses de novembro a abril), apresentando 
precipitação média de 431,8 mm/ano. A área é caracterizada por baixos índices pluviométricos e má distribuição das chuvas durante o período (Figura 4).

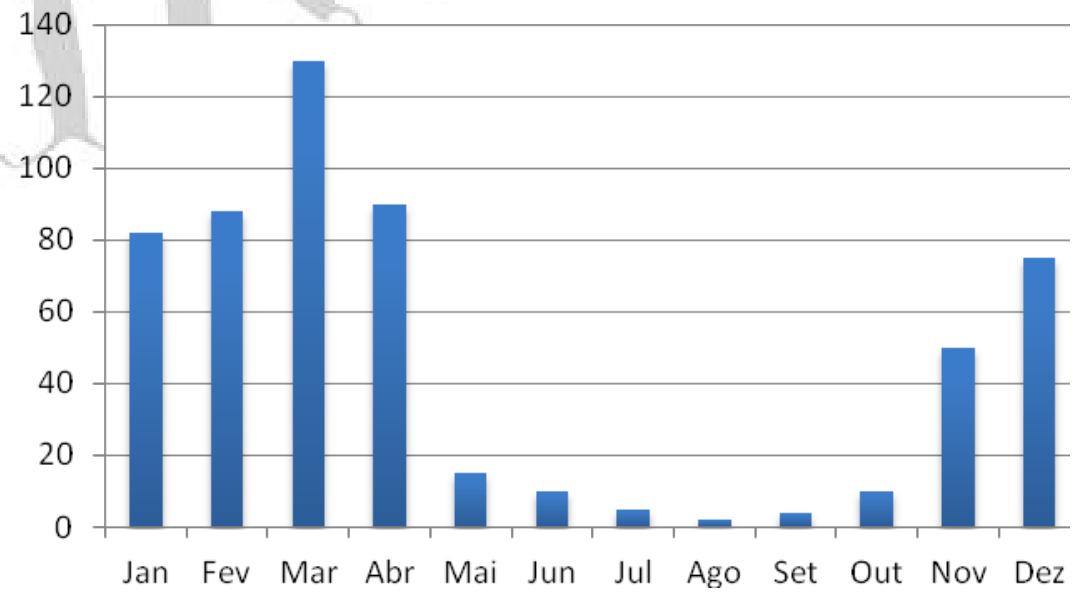

Figura 4: Histogramas de precipitação pluvial do período de 1963/2009 da estação agrometeorológicas de Bebedouro (Petrolina, PE). Fonte: Adaptado (TEIXEIRA, 2010).

\section{MATERIAIS E MÉTODOS}

\section{Trabalho de campo}

Foram realizados três trabalhos de campo com intuito de reconhecimento e coleta de material para a realização de Análises Sedimentológicas; Análise Geoquímica por Espectrometria de Fluorescência de Raios-X (FRX) e Análise Geocronológica (datação) por LOE protocolo SAR. 


\section{Coleta de Amostras}

Foram feitas as identificações em campo das áreas potenciais para a coleta das amostras. Nas áreas escolhidas foram cavadas pequenas trincheiras, ou aproveitados barrancos (neste caso foi realizada a limpeza do perfil. As amostras para análise das propriedades sedimentológicas foram coletadas em sacos plásticos, com cerca de $1 \mathrm{~kg}$ de amostra. Para a datação dos sedimentos, foram feitas coletas em tubos de PVC de cor preta, com $55 \mathrm{~cm}$ de comprimento e $5 \mathrm{~cm}$ de diâmetro. Os tubos foram introduzidos no sedimento evitando ao máximo a exposição à luz solar, sendo estes fechados com tampões pretos de plástico bem ajustado. As amostras para datação foram coletadas no mesmo nível do perfil que as amostras coletadas para análise sedimentológica, para permitir uma correlação cronoestratigráfica adequada com os sedimentos estudados

\section{Trabalho de laboratório}

As amostras de sedimentos foram coletadas nos perfis estratigráficos, para a realização, em laboratório das análises sedimentológicas. Os procedimentos de morfoscopia e granulometria foram realizados nas dependências do Laboratório de Geomorfologia do Quaternário no Departamento de Ciências Geográficas, Universidade Federal de Pernambuco. Os sedimentos foram datados no Laboratório do Grupo de Dosimetria e Instrumentação Nuclear da UFPE no Departamento de Energia Nuclear da UFPE. O Método utilizado para a datação foi o de Luminescência Opticamente Estimulada (LOE), o protocolo utilizado SAR, ou seja, o método de doses regenerativas utilizando uma única alíquota. 


\section{RESULTADOS E DISCUSSÕES}

\section{Evolução paleoambiental da margem esquerda da porção sub-média do rio} São Francisco

A partir dos dados sedimentares e cronológicos e relações de campo entre os sedimentos Coluviais, Flúvio-Eólicos e Eólicos (de origem Aluvial) inseridos nas bacias que margeiam o Rio São Francisco, é possível aventar a hipótese de que este rio passou por duas fases de menor carga hídrica durante o UMG, por volta de 30.400Ap e novamente próximo ao fim deste período expondo suprimento de areia de suas margens e canal para transporte eólico (Figura 5). Durante o UMG as áreas relacionadas às barras fluviais do Rio São Francisco serviram de fonte de sedimentos para a formação das áreas de dunas, e durante a transição Pleistoceno/Holoceno para formação de mantos de areia, devido à reumidificação climática, onde a torrencialidade das chuvas possivelmente destruiu as feições eólicas existentes, restando apenas um grande manto de areia posteriormente retrabalhado pelas cheias esporádicas do Rio São Francisco, servindo como fonte dos sedimentos que hoje formam os Latossolos e Argissolos que margeiam o Rio.

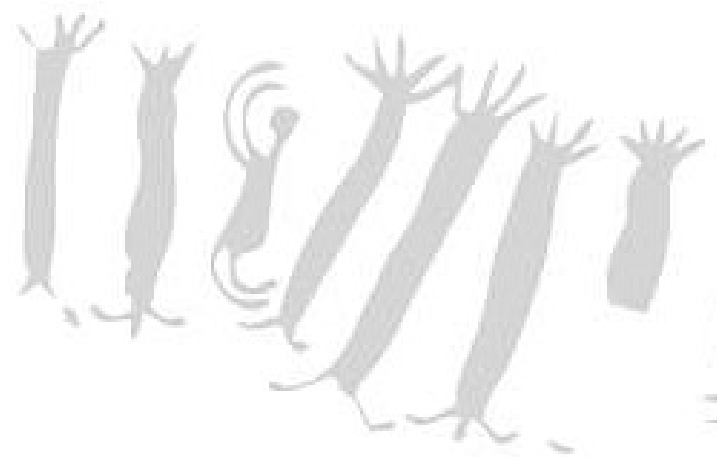




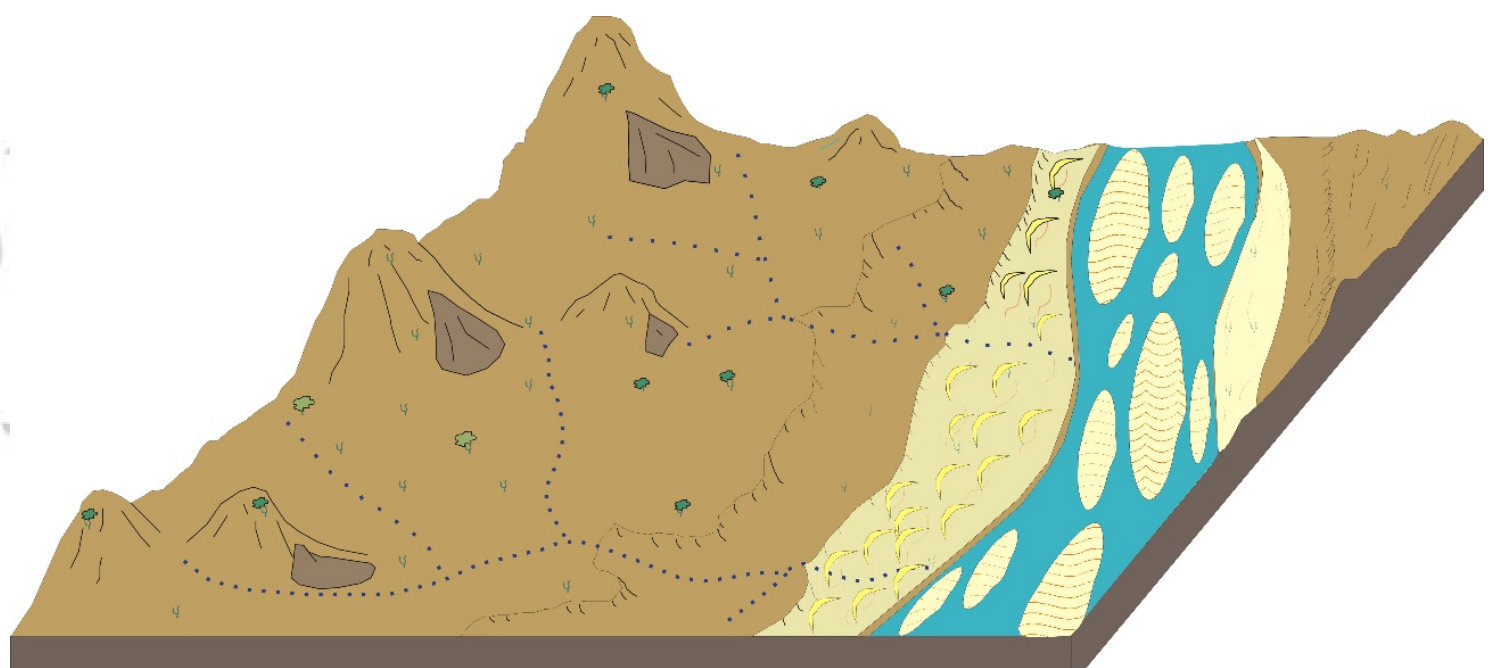

Figura 5: Bloco diagrama da área estudada durante o UMG e a transição Pleistoceno/Holoceno, evidenciando um clima mais seco que o atual, com atuação de eventos torrenciais com presença de uma vegetação esparsa (caatinga), relacionada com a semiaridez, e a presença de fluxos de lama antes que a cobertura vegetal se recuperasse da semiaridez do UMG.

Nota-se que os depósitos relacionados a esses solos, estão localizados em áreas planas e cortados pela drenagem. Logo é possível concluir que a antiga planície do Rio São Francisco, encontra-se sobre a delimitação das cotas topográficas de 350 a 400m (Figura 6 e 7) onde são determinados três níveis de antigos terraços fluviais, o mais antigo inferido primeiramente a partir do traçado de perfis topográficos onde foram identificadas pequenas rupturas de patamar, determinando assim antigos terraços fluviais assimilados pela paisagem e retrabalhados como pedimento. O material encontrado sobre esses terraços tem uma característica deposicional de extrapolação do leito fluvial, granulometria fina sem estrutura, típica de lagoas marginais (depósito de cheia, sem estruturas de 
transporte fluvial), datados do fim do Pleistoceno e associados à paleodinâmica do São Francisco.

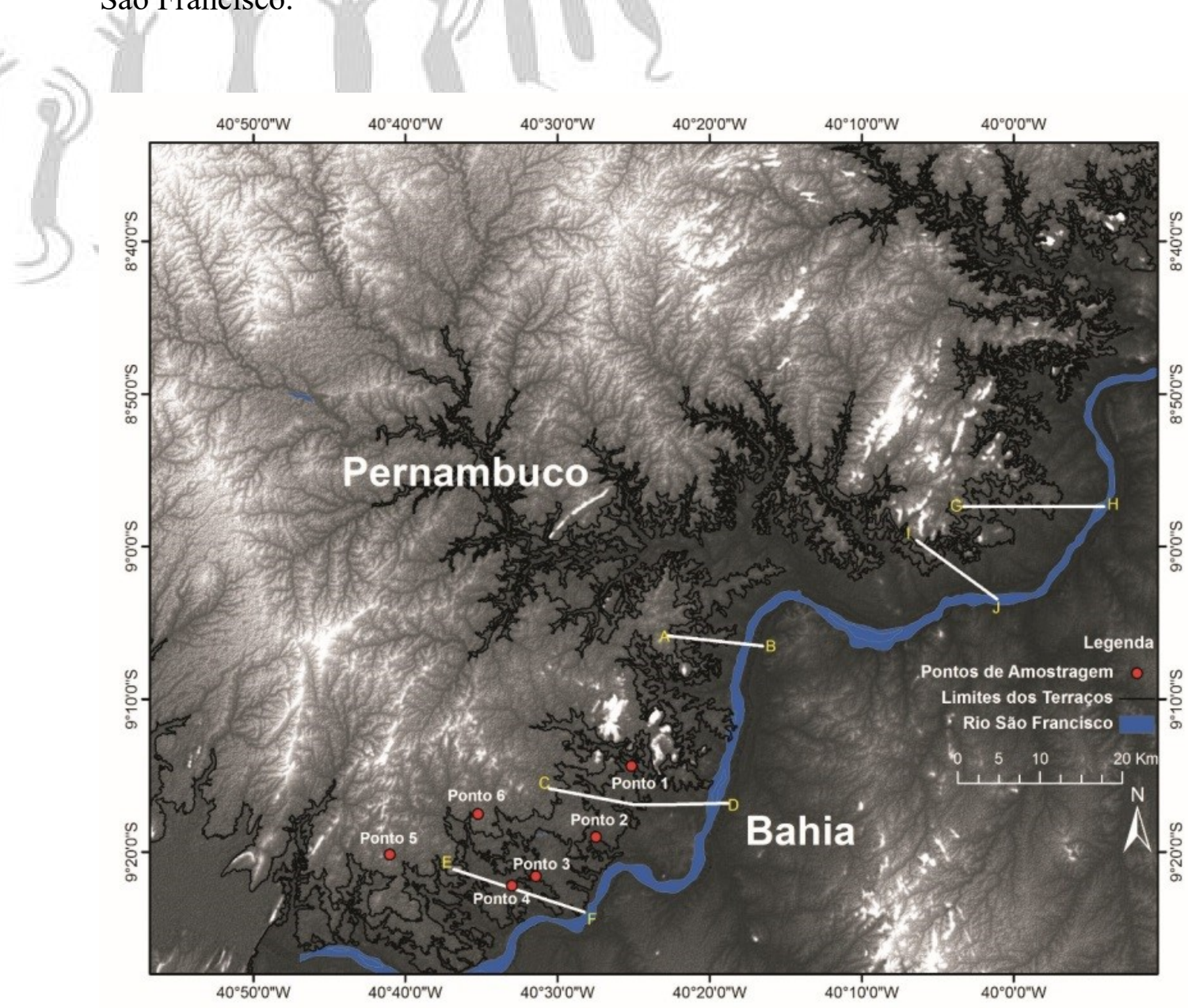

Figura 6: Mapa índice com os traçados dos perfis topográficos. 
Clio Arqueológica 2017, V32N3, p.107-134, LIRA.

DOI: 10.20891/clio.V32N3p107-134
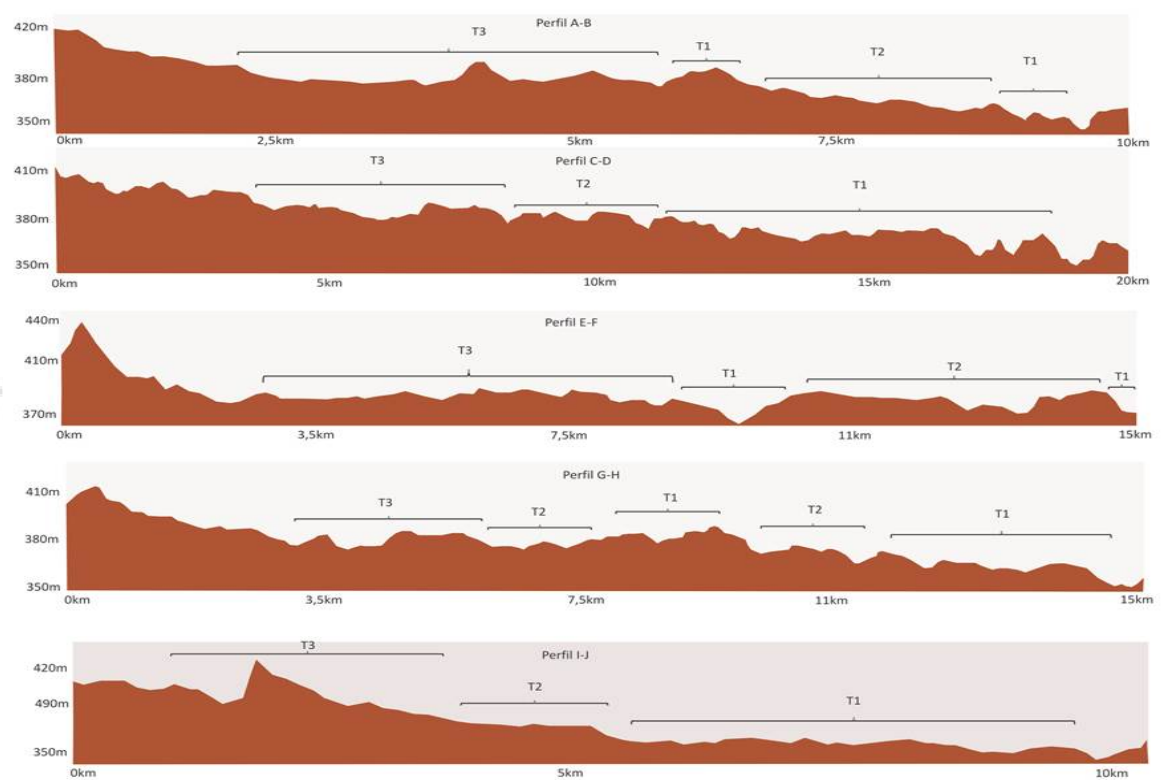

1

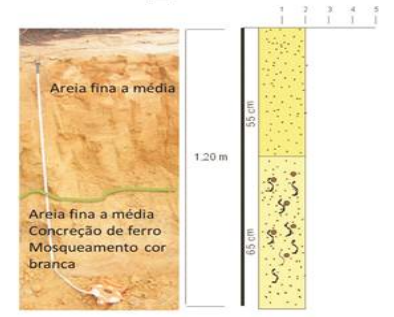

4
2

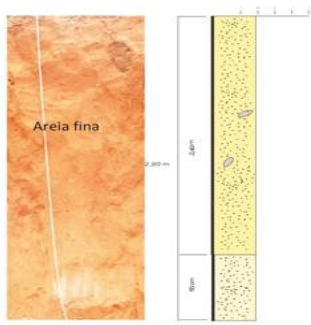

5
3

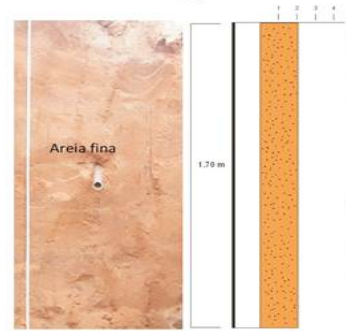

6

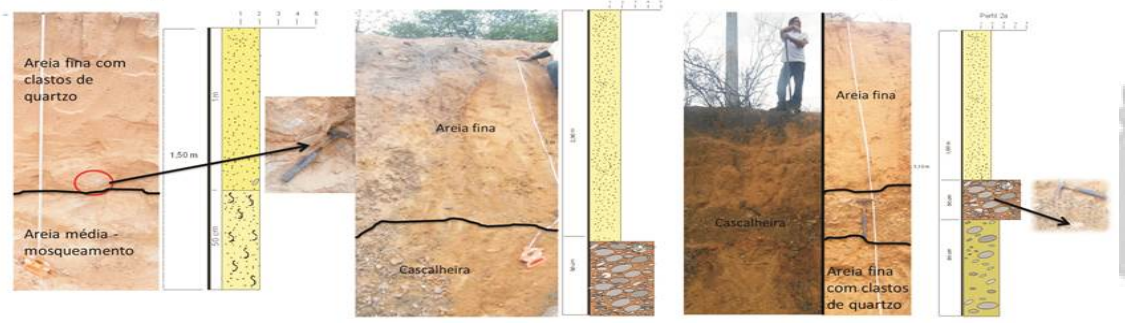

Figura 7. Delimitação dos terraços e a seção estratigráfica das áreas amostradas

Indexadores: Latindex, ISI, Google Scholar 
A Partir da Transição Pleistoceno/Holoceno, ocorre na área a instalação de um sistema de canais anastomosados. A figura 8 , ilustra a dinâmica desse sistema de canais anastomosados a partir da distribuição aloestratigráfica das unidades deposicionais encontradas em um perfil de $13 \mathrm{~km}$ inserido na Bacia GI8, no sentido NW-SE, em direção ao Rio São Francisco, a idade da cascalheira inserida entre dois pacotes sedimentares, pode ser obtida de forma relativa sendo estas geocronologicamente correlatas a outras deposições a montante, fruto de um depósito de paleocanal, enquanto a amostra correlata seria fruto do transbordamento deste mesmo canal depositando os sedimentos finos pela planície.

Durante esse período ocorreu também um aumento da sedimentação uma vez que o ambiente passa por um momento de histerese ao sair de uma fase de glaciação (Período mais seco e frio no hemisfério Sul) até a adaptação a nova situação climática. A partir daí o nível das águas do Rio São Francisco começa a subir, e essa subida está diretamente relacionada à melhoria climática local, durante a transição Pleistoceno Holoceno até o ápice no ótimo climático do Holoceno com precipitações alcançando médias de cerca de $1.100 \mathrm{~mm}$ de acordo com Pimentel (2013), (Figura 9). 


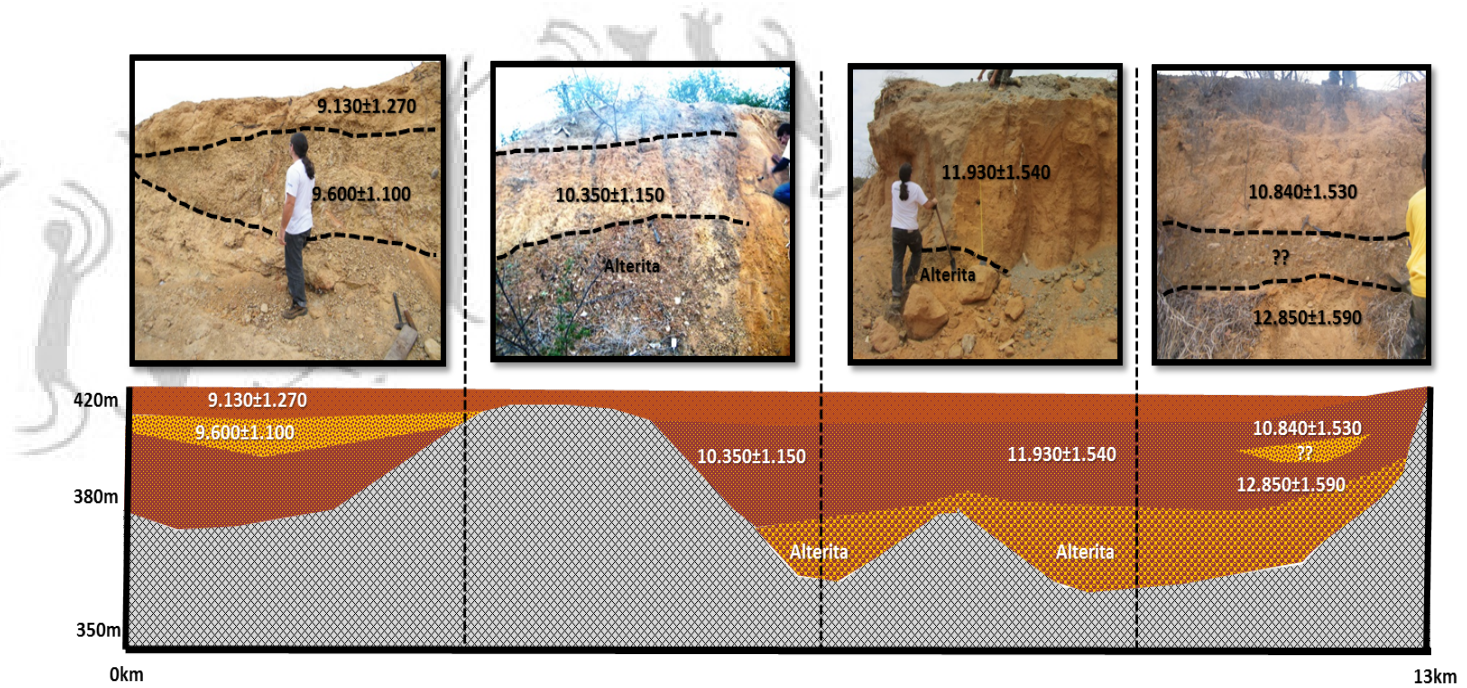

Figura 8: Perfil relativo a depósitos relacionados a um sistema de canais anastomosados, cascalheira, (paleocanal).

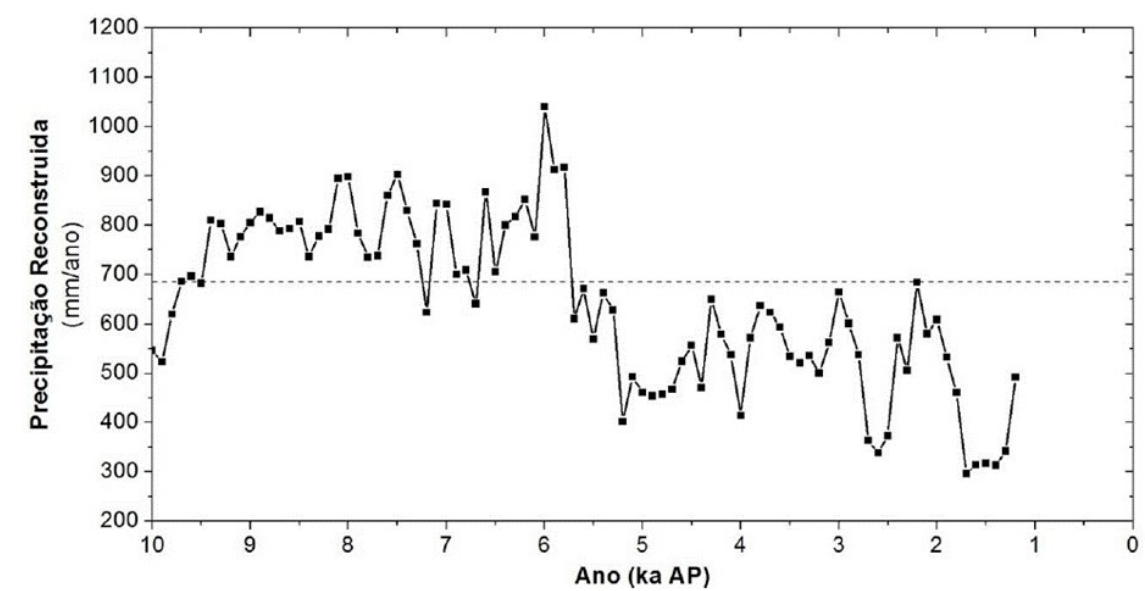

Figura 9: Reconstrução da precipitação referente ao acumulado total (Fevereiro; Março; Abril e Maio) em mm/ano e os eventos Bond ocorridos no Holoceno. A linha tracejada refere-se a média climatológica atual do volume de precipitação, $(680 \mathrm{~mm} / \mathrm{ano})$. Fonte: Pimentel (2013). 
Ótimo Climático do Holoceno, registrado na amostra coletada no segundo nível de terraço do Rio São Francisco, evidênciou a subida do nível de suas águas. Para esse período também se constatou um aumento de eventos gravitacionais relacionados a esse aumento de precipitação. A reumidificação desse período se explicita pela ausência de datas evidenciando atividade eólica, sendo mais comuns os eventos de coluvionamento (Figura 10) ou de extrapolação de leito do canal capazes de remobilizar as áreas de sedimentos eólicos, redepositando esses materiais.

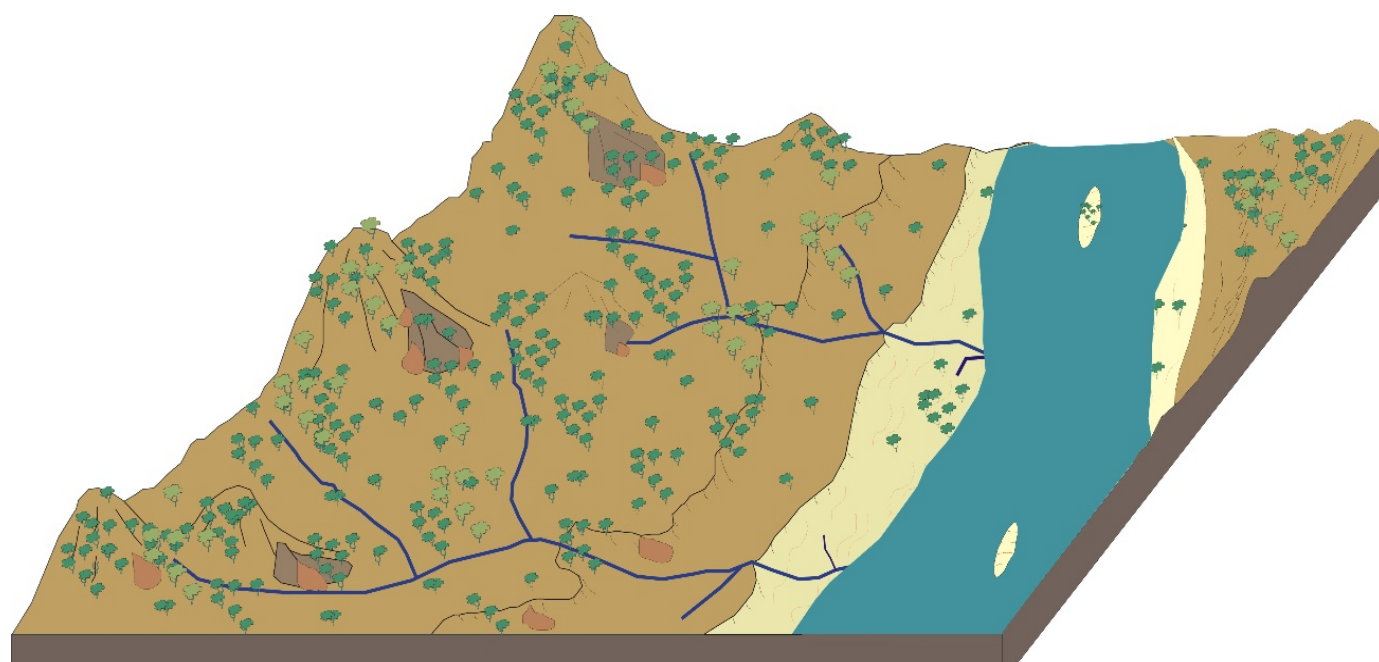

Figura 10: Bloco diagrama da área estudada durante a transição Pleistoceno/Holoceno, até o Ótimo Climático evidenciando um clima mais úmido que o atual, possibilitando a destruição dos campos de dunas, remoção dos mantos de intemperismo e retrabalhamento de depósitos já existentes na paisagem. 
As mudanças ambientais no Holoceno passam a ser controladas pela circulação atmosférica secundária, e por volta do Holoceno Médio corre novamente uma mudança rápida no clima, com a queda da umidade e padrões repetitivos de semiaridez severa alternados por uma semiaridez mais branda, provocada pela estabilização da célula de Walker, o que levou novamente a uma redução do nível das águas do Rio São Francisco, o que fica claro, com o resultado dos dados obtidos para os sedimentos eólicos, evidenciado uma queda da umidade e padrões repetitivos cíclicos de deposição/não deposição eólica controlados pela circulação do Pacifico Sul Tropical, marcada pelos sistemas auto regulados do tipo El Nino Oscilação Sul (ENOS). É possível identificar dois momentos de semiaridez severa, intercalado por um momento de melhoria climática por volta de registrado também por outros pesquisadores, como o segundo Ótimo Climático do Holoceno, essa melhoria climática é encontrada nesta região por destruindo as feições eólicas e retrabalhar o material sob a forma de mantos de areia.

\section{CONSIDERAÇÕES FINAIS}

Os Sedimentos estudados indicam gênese climática controlada por fatores da circulação geral da atmosfera em nível global e regional, revelando tele-conexões importantes desde o Último Máximo Glacial até a transição Pleistoceno/Holoceno, as mudanças ambientais na área foram controladas por eventos climáticos de escala global, verifica-se para o Nordeste Brasileiro essa transição adentra o Holoceno Inferior, por volta dos 9.000 até aproximadamente 8.800AP. 
Quanto às mudanças no Holoceno, essas são controladas pela circulação secundária, como a célula de Hadley e a estabilização da célula de Walker no Holoceno Médio trazendo uma queda da umidade e padrões repetitivos cíclicos de semiaridez severa e semiaridez moderada, relacionadas a eventos cíclicos do tipo El Nino/La Niña, controlados pela circulação do Pacifico sul tropical.

Com base nas análises realizadas é possível estabelecer algumas teleconexões, e reconstruir o quadro climático para a região estabelecendo a ocorrência de maior aridez do UMG, reumidificação na transição Pleistoceno/Holoceno, máximo da reumidificação no Holoceno Médio, ainda dentro do intervalo de relaxamento do sistema, e entrada no novo padrão de comportamento a partir do fim do Holoceno Médio com uma frequência repetitiva de episódios de semiaridez e aridez severa.

A análise detalhada das propriedades sedimentológicas dos materiais através da assinatura geoquímica, e estruturação das formas de relevo possibilitou a reconstrução dos processos de superfície terrestre atuantes na gênese dos modelados, durante os intervalos de relaxamento dos processos morfogenéticos mais agressivos.

Os depósitos relacionados aos Latossolos que integram a Planície do Rio São Francisco, são originados a partir da redução dos níveis das águas do Rio consequente surgimento de barras arenosas, que foram retrabalhadas pelo vento durante os períodos de maior semiaridez, formando campos de dunas e mantos de 
areia em períodos mais úmidos, sendo esses retrabalhados pelas águas do Rio São Francisco em momentos de cheias durante a transição Pleistoceno/Holoceno e o Ótimo Climático do Holoceno, dando origem a depósitos arenosos por toda a planície fluvial, onde hoje se estabelecem manchas de Latossolos e associações.

Os solos localizados em áreas planas referentes aos pedimentos detríticos, e mais distantes do Rio São Francisco, têm sua gênese relacionada a eventos gravitacionais que ocorreram durante o Pleistoceno Superior e Holoceno superior, período de maior umidade.

A reconstrução das dinâmicas de mecanismos formadores dos Latossolos em clima semiárido com ênfase temporal e paleoambiental através de estudos dos modelados de acumulação e denudação possibilitaram a reconstrução da dinâmica geomorfológica evidenciando a existência de controles climáticos temporais significativos e recorrentes no passado até os dias atuais.

A extrapolação dos resultados obtidos para os sistemas de superfície terrestre contemporâneos, cujas repercussões ambientais tornam-se importante para o Nordeste brasileiro, são sem dúvidas de grande interesse social. 


\section{REFERÊNCIAS BIBLIOGRÁFICAS}

AB'SABER, A.N. Revisão dos conhecimentos sobre o horizonte subsuperficial de cascalhos inumados do Brasil Oriental. Boletim da Universidade Federal do Paraná, Paraná, 1962, v. 2, p. 2-32.

AMIT, R. et al. Use of soils and colluvial deposits in analyzing tectonic events - The southern Arava Rift, Israel. Geomorphology, Elsevier, n. 12, p.91-107, 1995.

ÁVILA,F. F.; CARVALHO,V. L. M.. Morfogênese, pedogênese e etchplanação: análise integrada dos aspectos geoquímicos, mineralógicos e micromorfológicos dos solos de uma topossequência na Depressão de Gouveia - Serra do Espinhaço - Minas Gerais. Revista Brasileira de Geomorfologia, v.13, n.2, (Abr-Jun) p.223-233, 2012.

BEHLING, H. et al. Late Quaternary vegetational and climatic dynamics in northeastern Brazil, inferences from marine core GeoB 3104-1. Quaternary Science Reviews, v.19, p 981-994, 2002

BENNEMA, J.; CAMARGO, M.; WRIGHT, A. C. S. Regional contrast in South America soil formation in relation to soil classification and soil fertility. In: International Soil Conference, New Zealand, Int. Soc. Soil Science, p. 1-15, 1962.

BIGARELLA, J. \& MOUSINHO, M.R. Considerações a respeito dos terraços fluviais, rampas de colúvio e várzeas. Bol. Paranaense de Geografia 16 e 17, Curitiba, 1965a, 153197.

BIGARELlA, J. J. ANDRADE, G. O. Contribution to the study of the brasilian Quaternary. In: International studies of Quaternary. Geol. Soc. Amer. Special papers, 84, 1965.

BUOL, S.W.; HOLE, F.D. \& MC CRACKEN, R.J. Soil genesis and classification. Ames, Iowa State University Press, 1980. 404p.

Carnaúba-RN. Recife, UFPE. 2007.

CIOLKOSZ, E.J.; CARTER, B.J.; HOOVER, M.T.; CRONCE, R.C.; WALTMAN, W.J. DOBOS, R.R.,. Genesis of soils and landscapes in the Ridge and Valley province of central Pennsylvania. In: P.L.K. Knuepfer and L.D. McFadden (Editors), Soils and Landscape Evolution. Geomorphoiogy, 3:245-261. 1990. 
CORRÊA, A. C. B. Dinâmica geomorfológica dos compartimentos elevados do Planalto da Borborema, Nordeste do Brasil. Tese. (Tese de Doutorado) - Instituto de Geociências e Ciências Exatas, Universidade Estadual Paulista "Júlio de Mesquita Filho", Rio Claro. 2001.386p.

CORRÊA, A. C. B.; SILVA, D. G. da; MELO, J. S.. Utilização dos depósitos de encostas dos brejos pernambucanos como marcadores paleoclimáticos do quaternário tardio no semi-árido nordestino. Mercator - Revista de Geografia da UFC, ano 07, n. 14: 99-125, 2008.

do Alexandre: uma abordagem a partir da caracterização paleoambiental do vale do rio

GURGEL, S.P.P., BEZERRA, F. H. R.; CORRÊA, A. C. B.; MARQUES, F. O.; MAIA, R. P. Cenozoic uplift and erosion of structural landforms in NE Brazil, Geomorphology, Vol. 186, 68-84p. 2013.

KAISER, K., SCHOCH. W. H., MIEHE G.. Holocene paleosols and colluvial sediments in Northeast Tibet (Qinghai Province, China): Properties, dating and paleoenvironmental implications. Catena: An Interdisciplinary Journal of Soil Science, Hydrology, Geomorphology focusing on Geoecology and Landscape Evolution , Elsevier, n. 69, p.91-102, 2007.

KER, J.C.. Latossolos do Brasil: uma revisão. Geonomos, Vol. 5, n. 1. 17-40p. 1997.

LANG, A. Phases of soil erosion-derived colluviation in the loess hills of South Germany. Catena: An Interdisciplinary Journal of Soil Science, Hydrology, Geomorphology focusing on Geoecology and Landscape Evolution, Elsevier n. 51: 209$221,2003$.

MENEZES, J. B.; CORRÊA, A. C. B.; SILVA, F. F. da; ALVES, K. M. A. S.; ARAÚJO, M. S. B. Utilização de modelo digital de elevação para Identificação de possíveis áreasfontes de sedimentos Associados à ocorrência de latossolos no oeste Pernambucano. Congresso da ABEQUA, Belém do Pará, 2007.

MOTTA, P. E. F. da,; FILHO, A. de C.; KER, J. C.; PEREIRA, N. R.; JUNIOR, W. de C.; BLANCANEAUX, P.. Relações solo-superfície geomórfica e evolução da paisagem em uma área do Planalto Central Brasileiro. Pesq. agropec. bras, Brasília, v. 37, n. 6, p. 869-878, jun. 2002. 
MUTZENBERG, D. da S. Gênese e ocupação pré-histórica do sítio arqueológico Pedra

MUTZENBERG, D. S. Ambientes de Ocupação Pré-Histórica no Boqueirão da Pedra Furada, Parque Nacional Serra da Capivara - PI. Tese (Doutorado em de Arqueologia), Universidade Federal de Pernambuco, 2010. 256p.

QUEIROZ NETO, J.P. Geomorfologia e Pedologia. Revista Brasileira de Geomorfologia, vol. $1, \mathrm{n}^{\mathrm{o}} 1, \mathrm{p} .59-67.2000$,

QUEIROZ NETO, J.P. Relações entre as vertentes e os solos: Revisão de Conceitos. Revista Brasileira de Geomorfologia, v. 12, nº 3, p.15-24. 2011

SANTOS, C. T.; VIDAL, D. M.. Sistemas filtrantes para estabilização de colúvios Importância da estrutura do solo. Instituto Tecnológico de Aeronáutica. São José dos Campos - SP. 2003.

SANTOS, J. H. S.; SILVA, J. X. . Datação e evolução dos campos de dunas eólicas inativas dos Lençóis Maranhenses. In: XIII SBGFA, 2009, Viçosa-MG. XIII Simpósio Brasileiro de Geografia Física Aplicada, 2009. v. 1, p. 1-17.

SANTOS, M. J.; SALGADO, A. A. R. Gênese da Superfície Erosiva em Ambiente Semiárido - Milagres/BA: Considerações Preliminares. Revista de Geografia. Recife: UFPE - DCG/NAPA, v. especial VIII SINAGEO, n. 1, Set. 2010

SMOLSKA, E. Development of gullies and sediment fans in last-glacial areas on the example of the Suwałki Lakeland (NE Poland). Catena: An Interdisciplinary Journal of Soil Science, Hydrology, Geomorphology focusing on Geoecology and Landscape Evolution, Elsevier n. 71: 122-131, 2007.

SUGUIO, K. Geologia do quaternário e mudanças ambientais: passado + presente $=$ futuro? São Paulo: Paulo's comunicação e Artes gráficas, 2001. 366p. 